\title{
IDENTIFIKASI WASTE DENGAN METODE VALUE STREAM MAPPING DI BAGIAN PROSES PRODUKSI JELLY POWDER DI PT. KIANTAKA RASA
}

\author{
Tri Widodo, DwiJasela Utami \\ Prodi Teknik Industri Fakultas Teknik \\ Universitas Muhammadiyah Tangerang \\ Email : Tiga_wd@yahoo.co.id, Dwijasela13@gmail.com
}

\begin{abstract}
Abstrak
Proses produksi yang efektif dan efisien dapat memberikan nilai tambah untuk produk dan dapat menghasilkan produk yang dapat bersaing dengan kompetitor. Salah satu cara untuk mendesain proses produksi yang lebih efisien dan efektif yaitu meminimalisasi atau menghilangkan pemborosan yang terjadi. Salah satu alat yang digunakan untuk meminimalisasi adalah value stream mapping. Pengumpulan data dilakukan dengan pengamatan untuk perhitungan waktu siklus diolah menggunakan uji keseragaman data dan uji kecukupan data. Untuk menganalisasi penyebab pemborosan yang terjadi digunakan diagram fishbone. Proses produksi jelly powder membutuhkan waktu selama 6,274.08 detik untuk melakukan produksi 1 batch jelly powder. Waste yang terdeteksi setelah digambarkan dengan current state value stream mapping pada proses produksi jelly powder yaitu waste transportation, waiting dan motion. Penyebab waste yang terjadi karena jarak gedung yang cukup jauh, material handling terbatas, dan ruang produksi dan gudang yang berbeda lantai sehingga membutuhkan waktu lebih untuk proses selanjutnya. Usulan perbaikan yang akan dilakukan yaitu perlu penyediaan fasilitas komputer pada ruang produski, koordinasi antar operator gudang produksi, ruang produksi dan gudang dibuat disatu lantai bersamaan dan proses pengambilan sample dan packing dilakukan bersamaan dalam satu waktu. Setelah dilakukan usulan perbaikan, proses produksi jelly powder menjadi $5,188.08$ detik.
\end{abstract}

Kata Kunci : Nilai Tambah, Value Stream Mapping, Uji Keseragaman Data, Uji Kacukupan Data, Diagram Fishbone

\section{PENDAhULUAN}

\subsection{Latar Belakang}

Produk yang memiliki nilai tambah sangat penting bagi perusahaan. Untuk memberikan nilai tambah pada sebuah produk yaitu dapat mendesain proses produksi yang lebih efektif dan efisien. Salah satunya yaitu dengan mengurangi atau meminimalkan waste yang terjadi pada waste tersebut. Produksi jelly powder yang ada di PT. Kiantaka Rasa dinilai belum efektif dan efisien karena masih terdapat beberapa waste yang terjadi dalam proses tersebut sehingga waktu produksi yang dibutuhkan cukup lama dan target produksi tidak tercapai. Berdasarkan latar belakang tersebut, peneliti tertarik utnuk melakukan penelitian dengan judul "Identifikasi Waste dengan Metode Value Stream Mapping pada Bagian Produksi Jelly Powder di PT. Kiantaka Rasa". 


\subsection{Perumusan Masalah}

1. Apa saja waste yang terjadi pada proses produksi jelly powder?

2. Apa saja faktor-faktor penyebab yang mempengaruhi waste yang terjadi?

3. Bagaimana solusi untuk menghilangkan atau mengurangi waste pada proses produksi jelly powder?

\subsection{Tujuan Penelitian}

1. Mengetahui waste yang terjadi pada proses produksi jelly powder.

2. Mengetahui faktor-faktor penyebab yang mempengaruhi waste yang terjadi pada proses produksi.

3. Mengetahui solusi yang harus digunakan untuk menghilangkan atau mengurangi waste.

\section{TINJAUAN PUSTAKA}

Dalam era kompetisi sekarang ini, setiap perusahaan harus mampu meningkatkan kinerja perusahaan. Salah satu faktor penting yang harus diperhatikan oleh perusahaan dalam mencapai tujuannya adalah faktor sumber daya manusia (SDM). Manusia sebagai penggerak perusahaan merupakan faktor utama karena eksistensi perusahaan tergantung pada manusia-manusia yang terlibat dibelakangnya. Untuk dapat mencapai tujuan dari perusahaan maka diperlukan sumber daya manusia yang kompeten dalam melaksanakan tugasnya.

Bagi setiap perusahaan, karyawan bagian produksi merupakan sumber daya yang tidak kalah pentingnya dengan sumber daya perusahaan bagian yang lainnya. Karyawan dalam setiap organisasi memiliki tuntutan tugas-tugas yang merupakan salah satu aspek dari beban kerja. Beban kerja dapat didefinisikan sebagai perbedaan kemampuan pekerja dengan tuntutan pekerjaan (Hancock, P.A \& Meshkati, N. 1988). Jika kemampuan pekerja lebih tinggi daripada tuntutan pekerjaan, akan muncul perasaan bosan. Sebaliknya, jika kemampuan pekerja lebih rendah daripada tuntutan pekerjaan, maka akan muncul kelelahan.

Beban kerja menjadi salah satu indikasi penimbul stress, secara sederhana stress dipandang sebagai sesuatu yang melibatkan interaksi antara individu dengan lingkungan (Gibson, 1985). Dalam situasi kerja dikenal istilah stress kerja, menurut Wijono (2010) stres kerja merupakan suatu kondisi dari hasil penghayatan subjektif individu yang dapat berupa interaksi antara individu dan lingkungan kerja yang dapat mengancam dan memberikan tekanan secara psikologis, fisiologis, dan sikap individu, stress kerja ini menimbulkan permasalahan atau gejala dalam lingkungan pekerjaan, gejala-gejala fisiologi, psikologi maupun sikap. Perubahan fisiologi ditandai oleh adanya gejala-gejala seperti merasa lelah atau letih, kehabisan tenaga, pusing, gangguan pencernaan, sedangkan gejala psikologi yaitu kecemasan berlarut-larut dan sulit tidur, sedangkan perubahan sikap ditunjukan dengan keras kepala, mudah marah, dan tidak puas dengan apa yang dicapai.

PT Mitsubishi Chemical Indonesia (MCCI) adalah industri kimia yang bergerak di bidang petrokimia, dengan kata lain perusahaan tersebut mengelola bahan-bahan yang berskala dari fraksi minyak bumi. PT Mitsubishi Chemical Indonesia merupakan perusahaan asing yang memproduksi Asam Tereftalat (Purified Terephthalic Acid / PTA) yang menjadi bahan baku utama pembuatan polyester. Industri yang memproduksi PTA merupakan industri yang sarat akan modal. Meski demikian, bagian-bagian signifikansi dari produksinya membutuhkan input manusia. Produksi yang sesuai target serta kualitas yang baik merupakan kebutuhan perusahaan agar dapat terus bersaing dan mengibarkan benderanya.

Ada beberapa perusahaan di daerah Cilegon yang memproduksi PTA, diantaranya yaitu PT. Amoco Mitsui PTA Indonesia dan PT. Indorama Petrochemicals. Perusahaanperusahaan tersebut merupakan perusahaan pesaing dari MCCI yang memiliki tingkat kapasitas produksi yang tinggi. Posisi ini membuat perusahaan harus berusaha keras 
mempertahankan kapasitas produksi dan kualitas produknya agar terus dapat diterima oleh konsumen, masalah ini berhubungan dengan seksi produksi yang bertugas menjaga kestabilan proses produksi dengan baik. Pekerjaan ini menuntut ketelitian dan pengawasan ekstra agar menghasilkan produk sesuai dengan yang diinginkan.

Bidang kerja di seksi proses produksi di bagian Purified Terephtalic Acid (PTA) menuntut kebutuhan mental yang dominan, tugas kerja yang berlebih dan kurang teratur kerap menimbulkan masalah pada setiap individu seperti mudah lelah, stress dan sebagainya. Hal-hal tersebut dapat mempengaruhi kestabilan proses produksi yang merupakan salah satu indikator penilaian kinerja secara umum dalam seksi proses produksi di bagian Purified Terephtalic Acid (PTA).

Langkah-langkah penelitia ini adalah:

1. Pengolahan dan Pengujian Data Waktu Siklus

Waktu yang diambil menggunakan alat bantu stopwatch. Waktu siklus yang diperoleh perlu di uji keakuratannya melalui dua tahap, yaitu uji kecukupan data dan uji keseragaman data.

2. Pemetaan Proses Produksi dengan Current State Value Stream Mapping
a. Mengidentifikasi aliran informasi dan material
b. Membuat peta untuk setiap kategori proses
c. Membuat peta aliran keseluruhan pabrik

3. Identifikasi kegiatan VA, NVA dan NNVA Setelah penggambaran dengan curret state mapping, setiap kegiatan diidentikasi termasuk pada VA, NV atau NNVA.

4. Diagram Fishbone

Penyebab-penyebab waste yang terjadi dijelaskan menggunakan diagram fishbone.

5. Penggambaran Future State Value Stream Mapping

Setelah dilakukan usulan perbaikan, kemudian digambarkan dengan future state mapping.

\section{HASIL DAN PEMBAHASAN}

Pengolahan Data

Berikut adalah pengukuran waktu siklus pada proses-proses produksi jelly powder :

1. Pengambilan Job sheet ke Gedung A

Tabel 1 Pengukuran Waktu Siklus Pengambilan Job sheet ke Gedung A

\begin{tabular}{|c|c|c|c|c|}
\multirow{2}{*}{ Pengamatan } & \multicolumn{4}{|c|}{ Waktu Siklus (detik) } \\
\cline { 2 - 5 } & M1 & M2 & M3 & M4 \\
\hline 1 & 935 & 938 & 915 & 985 \\
\hline 2 & 948 & 1,011 & 956 & 1,004 \\
\hline 3 & 960 & 900 & 940 & 953 \\
\hline 4 & 928 & 927 & 943 & 924 \\
\hline
\end{tabular}

2. Pengambilan Bahan Baku ke Gudang

Tabel 2 Pengukuran Waktu Siklus Pengambilan Bahan Baku ke Gudang

\begin{tabular}{|c|l|l|l|l|}
\hline \multirow{2}{*}{ Pengamatan } & \multicolumn{4}{|c|}{ Waktu Siklus (detik) } \\
\cline { 2 - 5 } & M1 & M2 & M3 & M4 \\
\hline 1 & 625 & 711 & 705 & 636 \\
\hline 2 & 694 & 633 & 675 & 704 \\
\hline 3 & 629 & 626 & 626 & 720 \\
\hline 4 & 654 & 715 & 648 & 713 \\
\hline
\end{tabular}

3. Pemindahan bahan baku dari gudang ke ruang timbang

Tabel 3 Pengukuran WS Pemindahan Bahan Baku dari Gudang ke Ruang Timbang

\begin{tabular}{|c|c|c|c|c|}
\hline \multirow{2}{*}{ Pengamatan } & \multicolumn{4}{|c|}{ Waktu Siklus (detik) } \\
\cline { 2 - 5 } & M1 & M2 & M3 & M4 \\
\hline 1 & 331 & 316 & 335 & 330 \\
\hline 2 & 379 & 416 & 389 & 328 \\
\hline
\end{tabular}




\begin{tabular}{|l|l|l|l|l|}
\hline 3 & 328 & 390 & 348 & 354 \\
\hline 4 & 345 & 397 & 315 & 360 \\
\hline
\end{tabular}

4. Penimbangan Bahan Baku

Tabel 4 Pengukuran Waktu Siklus Penimbangan Bahan Baku

\begin{tabular}{|c|l|c|c|c|}
\hline \multirow{2}{*}{ Pengamatan } & \multicolumn{4}{|l|}{ Waktu Siklus (detik) } \\
\cline { 2 - 5 } & M1 & M2 & M3 & M4 \\
\hline 1 & 935 & 955 & 944 & 986 \\
\hline 2 & 942 & 943 & 929 & 993 \\
\hline 3 & 988 & 988 & 995 & 1,010 \\
\hline 4 & 1,003 & 915 & 940 & 945 \\
\hline
\end{tabular}

5. Pemindahan Bahan Baku dari Ruang Timbang ke Ruang Produksi

Tabel 5 Pengukuran WS Pemindahan Bahan Baku dari Ruang Timbang ke Ruang

Produksi

\begin{tabular}{|c|c|c|c|c|}
\hline \multirow{2}{*}{ Pengamatan } & \multicolumn{4}{|c|}{ Waktu Siklus (detik) } \\
\cline { 2 - 5 } & M1 & M2 & M3 & M4 \\
\hline 1 & 225 & 223 & 218 & 200 \\
\hline 2 & 197 & 199 & 225 & 195 \\
\hline 3 & 209 & 233 & 214 & 213 \\
\hline 4 & 223 & 206 & 220 & 208 \\
\hline
\end{tabular}

6. Pemindahan Bahan Baku dari Pallet ke Mesin Mixing

Tabel 6 Pengukuran WS Proses Pemindahan Bahan Baku dari Pallet ke Mesin Mixing

\begin{tabular}{|c|l|l|l|l|}
\hline \multirow{2}{*}{ engamatan } & \multicolumn{4}{|c|}{ Waktu Siklus (detik) } \\
\cline { 2 - 5 } & M1 & M2 & M3 & M4 \\
\hline 1 & 197 & 214 & 225 & 225 \\
\hline 2 & 234 & 209 & 218 & 236 \\
\hline 3 & 210 & 215 & 208 & 207 \\
\hline 4 & 218 & 205 & 228 & 213 \\
\hline
\end{tabular}

7. Penuangan Bahan Baku ke Mesin Mixing

Tabel 7 Pengukuran Waktu Siklus Proses Penuangan Bahan Baku ke Mesin Mixing

\begin{tabular}{|c|c|c|c|c|}
\hline \multirow{2}{*}{ Pengamatan } & \multicolumn{4}{|c|}{ Waktu Siklus (detik) } \\
\cline { 2 - 5 } & M1 & M2 & M3 & M4 \\
\hline 1 & 288 & 268 & 270 & 285 \\
\hline 2 & 275 & 276 & 273 & 275 \\
\hline 3 & 268 & 280 & 280 & 267 \\
\hline 4 & 275 & 294 & 279 & 265 \\
\hline
\end{tabular}

8. $\quad$ Proses Mixing

Tabel 8 Pengukuran Waktu Siklus Proses Mixing mencukupi.

\begin{tabular}{|c|c|c|c|c|}
\hline \multirow{2}{*}{ Pengamatan } & \multicolumn{4}{|c|}{ Waktu Siklus (detik) } \\
\cline { 2 - 5 } & M1 & M2 & M3 & M4 \\
\hline 1 & 1,800 & 1,800 & 1,800 & 1,800 \\
\hline 2 & 1,800 & 1,800 & 1,800 & 1,800 \\
\hline 3 & 1,800 & 1,800 & 1,800 & 1,800 \\
\hline 4 & 1,800 & 1,800 & 1,800 & 1,800 \\
\hline
\end{tabular}

9. Pengambilan Sample

Tabel 9 Pengukuran Waktu Siklus Proses Pengambilan Sample

\begin{tabular}{|c|l|l|l|l|}
\hline \multirow{2}{*}{ engamatan } & \multicolumn{4}{l}{ Waktu Siklus (detik) } \\
\cline { 2 - 5 } & M1 & M2 & M3 & M4 \\
\hline 1 & 272 & 285 & 296 & 266 \\
\hline 2 & 265 & 256 & 292 & 297 \\
\hline 3 & 296 & 273 & 298 & 272 \\
\hline 4 & 275 & 268 & 272 & 266 \\
\hline
\end{tabular}


10. Proses Packing

Tabel 10 Pengukuran Waktu Siklus Proses Packing

\begin{tabular}{|c|c|c|c|c|}
\hline \multirow{2}{*}{ Pengamatan } & \multicolumn{4}{|c|}{ Waktu Siklus (detik) } \\
\cline { 2 - 5 } & M1 & M2 & M3 & M4 \\
\hline 1 & 345 & 345 & 347 & 328 \\
\hline 2 & 325 & 325 & 352 & 319 \\
\hline 3 & 354 & 349 & 331 & 332 \\
\hline 4 & 338 & 328 & 340 & 322 \\
\hline
\end{tabular}

11. Pemindahan Produk Jadi ke Gudang

Tabel 11 Pengukuran Waktu Siklus Proses Pemindahan Produk Jadi ke Gudang

\begin{tabular}{|c|c|c|c|c|}
\hline \multirow{2}{*}{ Pengamatan } & \multicolumn{4}{|c|}{ Waktu Siklus (detik) } \\
\cline { 2 - 5 } & M1 & M2 & M3 & M4 \\
\hline 1 & 235 & 225 & 209 & 208 \\
\hline 2 & 208 & 205 & 228 & 199 \\
\hline 3 & 234 & 215 & 211 & 216 \\
\hline 4 & 218 & 194 & 220 & 234 \\
\hline
\end{tabular}

Pengujian Data

Uji Kecukupan Data

Data-data waktu siklus kemudian diuji dengan uji kecukupan data dihasilkan $\mathrm{N}^{\prime}<\mathrm{N}$ dapat dinyatakan bahawa data yang digunakan sudah

Tabel 12 Rekapitulasi Hasil Uji Kecukupan Data pada Proses Produksi Jelly Powder

\begin{tabular}{|c|l|r|c|c|}
\hline No & \multicolumn{1}{|c|}{ Proses } & $\mathrm{N}^{\prime}$ & $\mathrm{N}^{\prime}$ & Keterangan \\
\hline 1 & Pengambilan Job sheet ke gedung A & 16 & 1.68 & Data Cukup \\
\hline 2 & Pengambilan bahan baku & 16 & 4.85 & Data Cukup \\
\hline 3 & $\begin{array}{l}\text { Pemindahan bahan baku dari gudang ke ruang } \\
\text { timbang }\end{array}$ & 16 & 11.57 & Data Cukup \\
\hline 4 & Penimbangan bahan baku di ruang timbang & 16 & 1.51 & Data Cukup \\
\hline 5 & $\begin{array}{l}\text { pemindahan bahan baku dari ruang timbang ke } \\
\text { ruang produksi }\end{array}$ & 16 & 1.78 & Data Cukup \\
\hline 6 & $\begin{array}{l}\text { pemindahan bahan baku dari palet ke mesin } \\
\text { mixing }\end{array}$ & 16 & 1.53 & Data Cukup \\
\hline 7 & penuangan bahan baku ke mesin mixing & 16 & 0.48 & Data Cukup \\
\hline 8 & proses mixing jelly powder & 16 & 0 & Data Cukup \\
\hline 9 & Pengambilan sample & 16 & 1.47 & Data Cukup \\
\hline 10 & Proses Packing & 16 & 0.69 & Data Cukup \\
\hline 11 & Pemindahan produk jadi ke gudang & 16 & 2.08 & Data Cukup \\
\hline
\end{tabular}

Uji Keseragaman Data

Setelah dilakukan uji kecukupan data, dilanjutkan dengan uji keseragaman data. Dihasilkan bahwa keseluruhan data masih dlam batas control.

Tabel 13 Rekapitulasi Hasil Uji Keseragaman Data pada Proses Produksi Jelly Powder

\begin{tabular}{|c|l|c|}
\hline No & \multicolumn{1}{|c|}{ Proses } & Keterangan \\
\hline 1 & Pengambilan Job sheet ke gedung A & Seragam \\
\hline 2 & Pengambilan bahan baku & Seragam \\
\hline 3 & Pemindahan bahan baku dari gudang ke ruang timbang & Seragam \\
\hline 4 & Penimbangan bahan baku di ruang timbang & Seragam \\
\hline 5 & pemindahan bahan baku dari ruang timbang ke ruang produksi & Seragam \\
\hline 6 & pemindahan bahan baku dari palet ke mesin mixing & Seragam \\
\hline 7 & penuangan bahan baku ke mesin mixing & Seragam \\
\hline 8 & proses mixing jelly powder & Seragam \\
\hline 9 & Pengambilan sample & Seragam \\
\hline 10 & Proses Packing & Seragam \\
\hline 11 & Pemindahan produk jadi ke gudang & Seragam \\
\hline
\end{tabular}


Identifikasi Waste dengan Process Activity Mapping

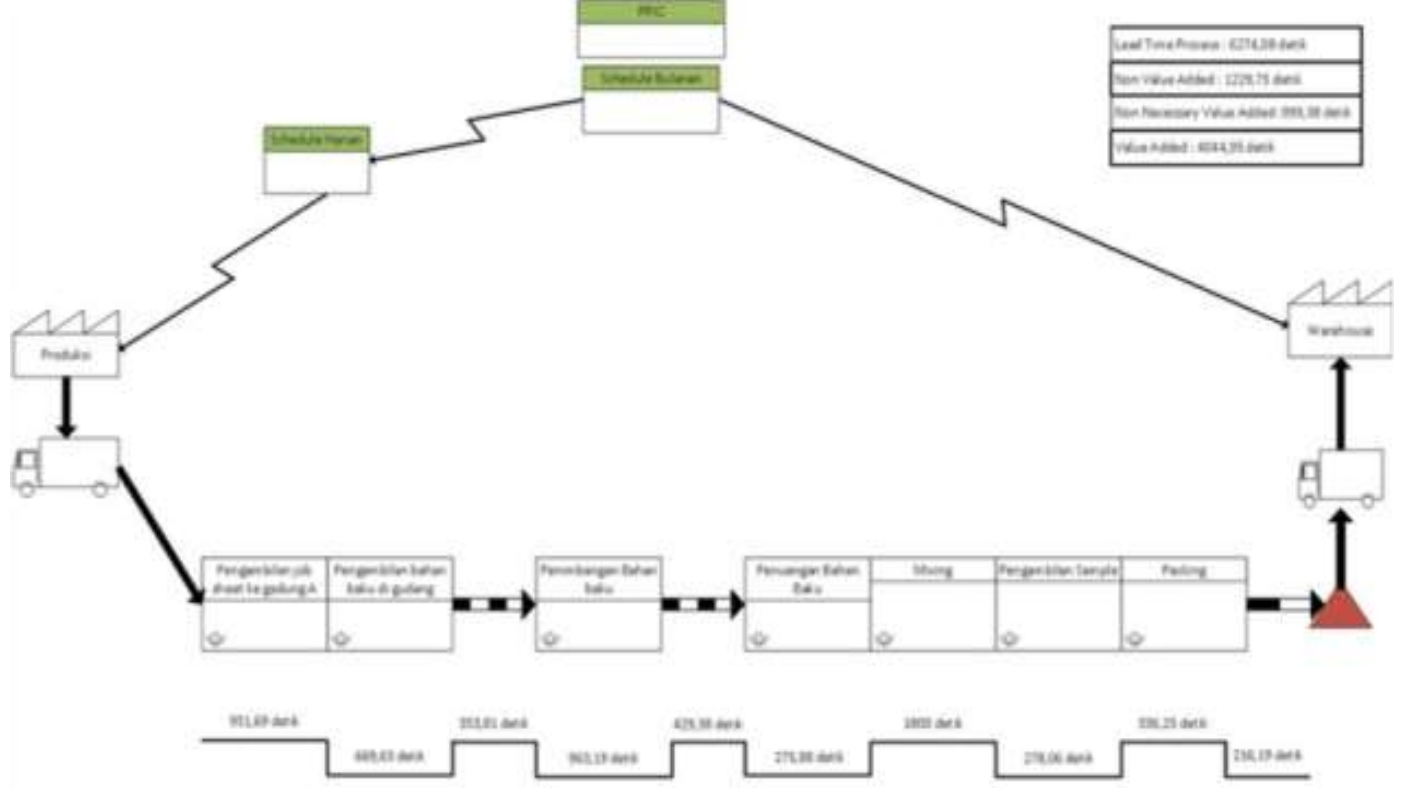

Gambar 1 Current State Value Stream Mapping

Tabel 15 Identifikasi Value Added, Non Value Added dan Necessary but Non Value Added dalam proses produksi jelly powder

\begin{tabular}{|c|c|c|c|c|c|}
\hline No & Kegiatan & Aktivitas & $\begin{array}{l}\text { Waktu } \\
\text { (detik) }\end{array}$ & Persentase & VA/NVA \\
\hline 1 & \multirow{11}{*}{$\begin{array}{l}\text { Produksi } \\
\text { Jelly } \\
\text { Powder }\end{array}$} & $\begin{array}{l}\text { Pengambilan job sheet di } \\
\text { gedung A }\end{array}$ & 951.69 & $15,17 \%$ & NVA \\
\hline 2 & & $\begin{array}{l}\text { Pengambilan bahan baku } \\
\text { digudang }\end{array}$ & 669.63 & $10,67 \%$ & VA \\
\hline 3 & & $\begin{array}{l}\text { Pemindahan bahan baku dari } \\
\text { gudang ke ruang timbang }\end{array}$ & 353.81 & $5,64 \%$ & NNVA \\
\hline 4 & & Penimbangan bahan baku & 963.19 & $15,35 \%$ & VA \\
\hline 5 & & $\begin{array}{l}\text { Pemindahan bahan baku dari } \\
\text { ruang timbang ke ruang } \\
\text { produksi }\end{array}$ & 213 & $3,40 \%$ & NNVA \\
\hline 6 & & $\begin{array}{l}\text { Pemindahan bahan baku dari } \\
\text { pallet ke mesin mixing }\end{array}$ & 216.38 & $3,45 \%$ & NNVA \\
\hline 7 & & $\begin{array}{l}\text { Penuangan Bahan Baku Ke } \\
\text { Mesin Mixing }\end{array}$ & 275.88 & $4,40 \%$ & VA \\
\hline 8 & & Proses Mixing & $1,800.00$ & $28,70 \%$ & VA \\
\hline 9 & & Pengambilan sample & 278.06 & $4,43 \%$ & NVA \\
\hline 10 & & Proses packing & 336.25 & $5,35 \%$ & VA \\
\hline 11 & & $\begin{array}{l}\text { Pemindahan produk jadi ke } \\
\text { gudang }\end{array}$ & 216.19 & $3,44 \%$ & NNVA \\
\hline \multicolumn{3}{|r|}{ Jumlah Lead Time } & \begin{tabular}{|c|}
$6,274.08$ \\
detik
\end{tabular} \mid & $100 \%$ & \\
\hline
\end{tabular}

Dari hasil pengelompokkan proses berdasarkan aktivitas diatas maka dapat dilihat pada tabel berikut ini :

Tabel 5 Data Kelompok Identifikasi Value Added, Non Value Added dan Necessary but 
Non Value Added dalam proses produksi jelly powder

\begin{tabular}{|l|c|c|c|}
\hline Aktivitas & Jumlah & Total Waktu (detik) & Persentase \\
\hline VA & 5 & $4,044.95$ & $64,47 \%$ \\
\hline NVA & 2 & $1,229.75$ & $19,60 \%$ \\
\hline NNVA & 4 & 999.38 & $15,92 \%$ \\
\hline Total & 11 & $6,274.08$ & $100 \%$ \\
\hline
\end{tabular}

Diagram Fishbone

Setelah mendapatkan waste apa saja yang terjadi dalam proses produksi jelly powder.

Berikut adalah waste dan penyebabnya yang dapat dilihat pada gambar ini :

1. Waiting

Beberapa penyebab terjadinya waste waiting dapat dilihat pada gambar :
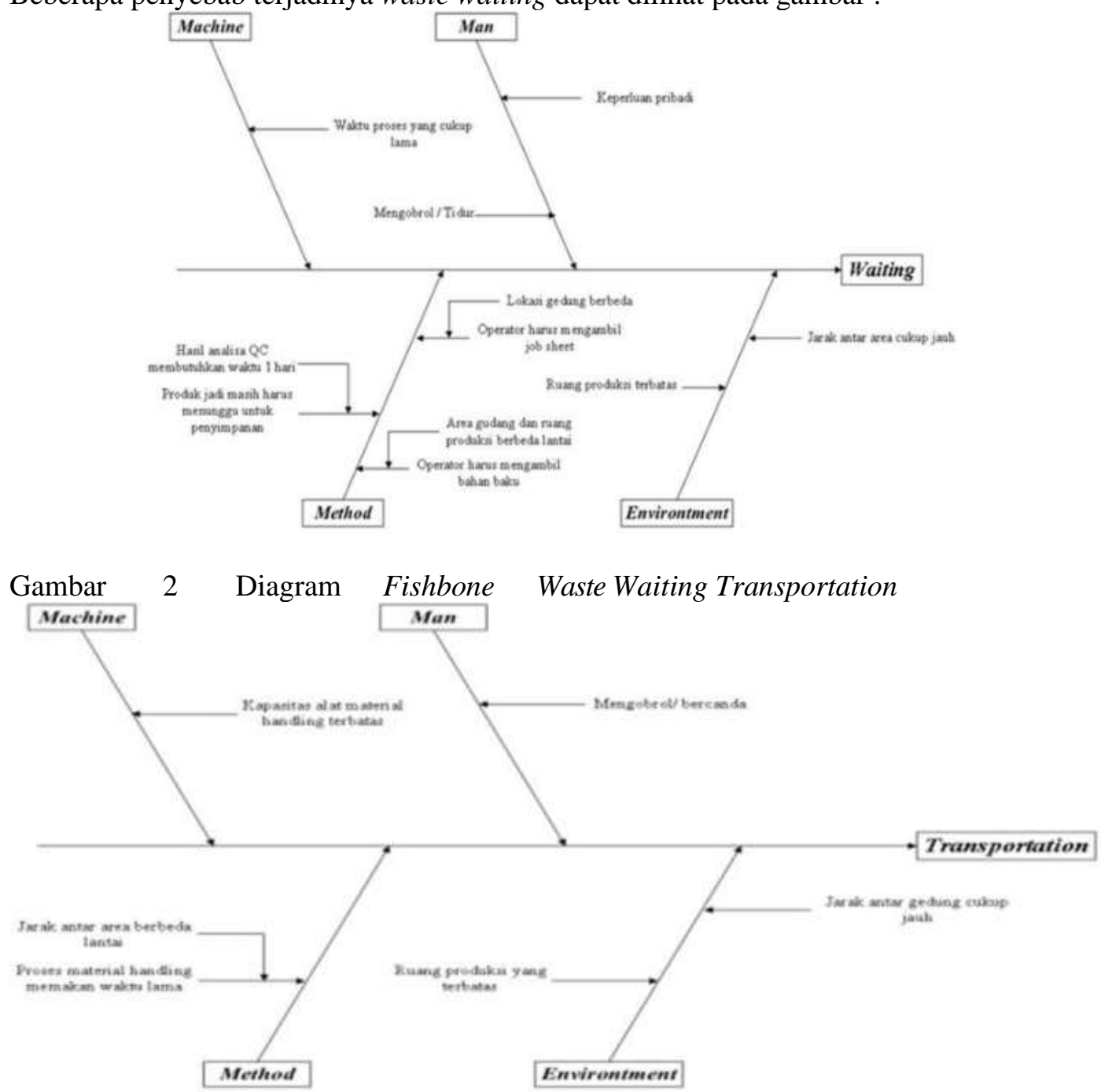

Beberapa penyebab terjadinya waste waiting dapat dilihat pada gambar :

Gambar 3 Diagram Fishbone Waste Transportation

Usulan Perbaikan

1. Penambahan fasilitas komputer

Pada proses produksi jelly powder, setiap pagi operator harus mengambil job sheet ke gedung A yang membutuhkan waktu lebih kurang 15 menit. Oleh karena itu sebaiknya perlu penambahan fasilitas berupa komputer yang dapat diletakkan diruang produksi untuk memudahkan operator melihat jadwal dan bahan baku yang dibutuhkan untuk produksi hari itu sehingga operator bisa langsung melakukan persiapan dan penimbangan bahan baku.

2. Koordinasi antar operator gudang bahan baku dan operator produksi 
Diperlukan koordinasi untuk operator gudang bahan baku dan opearotr produksi karena selama ini untuk pengmabilan bahan baku ke gudang masih dilakukan oleh operator produksi langsung. Sebaiknya operator gudang menyiapkan bahan baku dan langsung dikirim ke ruang timbang sehingga untuk melkakukan proses selanjutnya tidak membutuhkan waktu menunggu yang cukup lama.

3. Perbaikan tata letak area gudang dan area produksi

Kondisi area produksi yang berada pada lantai 2 membuat proses pemindahan bahan baku yang membutuhkan waktu cukup lama karena memerlukan material handling troli yang kemudian dinaikkan dengan lift barang. Sebaiknya, area produksi dan area gudang dibuat bersebelahan atau satu lantai agar waktu yang dibutuhkan untuk proses pemindahan bahan baku lebih efisien

4. Penggabungan proses pengambilan sample dan proses packing

Proses pengambilan sample yang dilakukan oleh quality control sebelum melakukan proses packing membutuhkan waktu lebih kurang selama 5 menit. Sebaiknya proses tersebut dapat digabungkan dnegan proses packing karena lebih menghemat waktu yang digunakan karena setelah diambil sample, produk bisa langsung dipacking secara bersamaan.

Future State Value Stream Mapping Setelah dilakukan usulan perbaikan, digambarkan ada future state value stream mapping sebagai berikut :

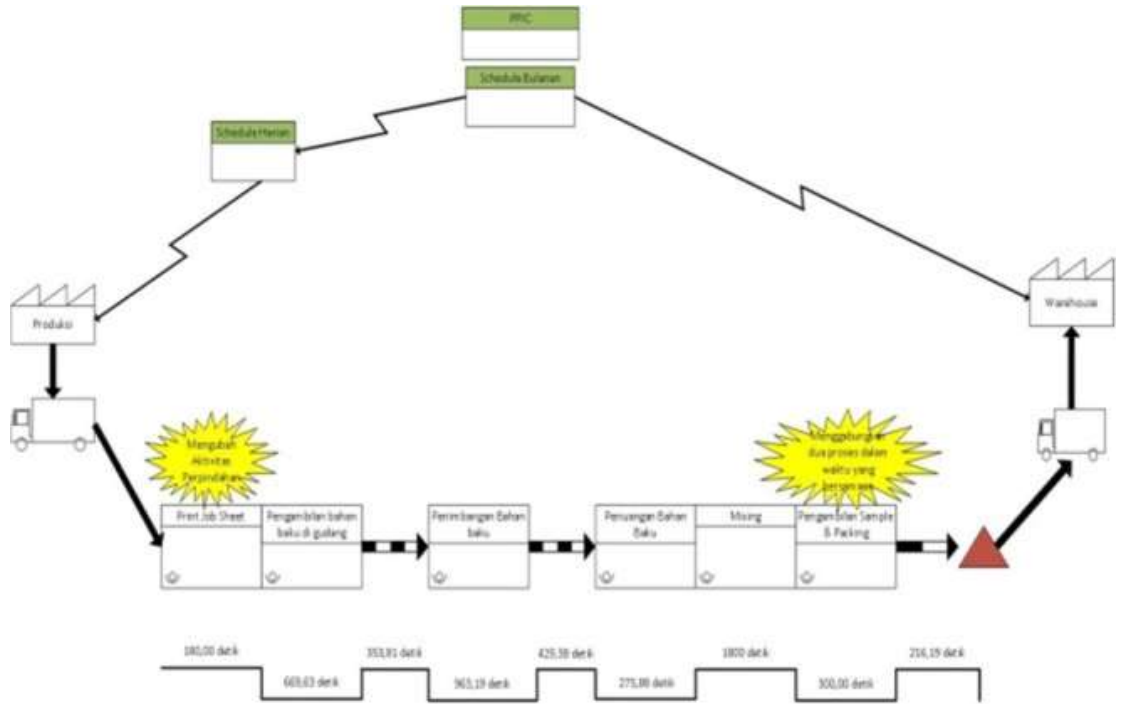

Gambar 4 Future State Value stream Mapping

Tabel 15 Identifikasi Value Added, Non Value Added dan Necessary but Non Value Added dalam proses produksi jelly powder setelah perbaikan

\begin{tabular}{|c|c|c|c|c|c|}
\hline No & Kegiatan & Aktivitas & $\begin{array}{l}\text { Waktu } \\
\text { (detik) }\end{array}$ & Persentase & VA/NVA \\
\hline 1 & \multirow{5}{*}{$\begin{array}{l}\text { Produksi } \\
\text { Jelly } \\
\text { Powder }\end{array}$} & $\begin{array}{l}\text { Pengambilan job sheet di } \\
\text { gedung A }\end{array}$ & 180 & $3,47 \%$ & VA \\
\hline 2 & & $\begin{array}{l}\text { Pengambilan bahan baku } \\
\text { digudang }\end{array}$ & 669.63 & $12,91 \%$ & $\overline{\mathrm{VA}}$ \\
\hline 3 & & $\begin{array}{l}\text { Pemindahan bahan baku dari } \\
\text { gudang ke ruang } \\
\text { timbang }\end{array}$ & 353.81 & $6,82 \%$ & NNVA \\
\hline 4 & & Penimbangan bahan baku & 963.19 & $18,57 \%$ & $\mathrm{VA}$ \\
\hline 5 & & $\begin{array}{l}\text { Pemindahan bahan baku dari } \\
\text { ruang timbang ke }\end{array}$ & 213 & $4,11 \%$ & NNVA \\
\hline
\end{tabular}




\begin{tabular}{|c|c|c|c|c|}
\hline & ruang produksi & & & \\
\hline 6 & $\begin{array}{l}\text { Pemindahan bahan baku dari } \\
\text { pallet ke mesinmixing }\end{array}$ & 216.38 & $4,17 \%$ & NNVA \\
\hline 7 & $\begin{array}{l}\text { Penuangan Bahan Baku } \\
\text { Ke Mesin Mixing }\end{array}$ & 275.88 & $5,32 \%$ & VA \\
\hline 8 & Proses Mixing & $1,800.00$ & $34,69 \%$ & VA \\
\hline 9 & $\begin{array}{l}\text { Pengambilan sample dan } \\
\text { proses packing }\end{array}$ & 300 & $5,78 \%$ & VA \\
\hline 10 & $\begin{array}{l}\text { Pemindahan produk jadi } \\
\text { ke gudang }\end{array}$ & 216.19 & $4,16 \%$ & NNVA \\
\hline \multicolumn{2}{|c|}{ Jumlah Lead Time } & $\begin{array}{l}5,188.08 \\
\text { detik }\end{array}$ & $100 \%$ & \\
\hline
\end{tabular}

Berikut perbandingan sebelum perbaikan dan setelah perbaikan pada tabel dibawah ini: Tabel 4.16 Data Perbandingan Sebelum dan Sesudah Perbaikan

\begin{tabular}{|c|c|c|r|r|c|c|}
\hline \multirow{2}{*}{ Aktivitas } & \multicolumn{2}{|c|}{ Jumlah } & \multicolumn{2}{c|}{ Total Waktu (detik) } & \multicolumn{2}{c|}{ Persentase } \\
\cline { 2 - 7 } & Sebelum & Sesudah & \multicolumn{1}{c|}{ Sebelum } & \multicolumn{1}{c|}{ Sesudah } & Sebelum & Sesudah \\
\hline VA & 5 & 7 & $4,044.95$ & $4,188.70$ & $64,47 \%$ & $80,74 \%$ \\
\hline NVA & 2 & - & $1,229.75$ & - & $19,60 \%$ & - \\
\hline NNVA & 4 & 4 & 999.38 & 999.38 & $15,92 \%$ & $19,26 \%$ \\
\hline Total & 11 & 11 & $6,274.08$ & $5,188.08$ & $100 \%$ & $100 \%$ \\
\hline
\end{tabular}

Dapat dilihat pada tabel 4.16 bahwa waktu proses pengambilan job sheet ke gedung A dari data awal 951.69 detik berkurang menjadi 180.00 detik. Untuk proses pengambilan sample dan proses packing

digabung menjadi satu menjadi 300.00 detik. Dari future state yang sudah dibuat dapat dilihat bahwa adanya perbedaan waktu yang dihasilkan. Proses yang terjadi menjadi lebih cepat atau menghemat waktu sebanyak $17,3 \%$ dari current state Pengurangan waktu yang terjadi dari sebelum 6,274.08 detik menjadi 5,188.08 detik. Bukan tidak mungkin waktu produksi ini dapat di minimasi lagi apabila usulan-usulan perbaikan dapat diterapkan dan di maksimalkan dengan baik.

\section{SIMPULAN DAN SARAN}

\section{Kesimpulan}

a. Penelitian ini menggunakan dimensi dari metode SWAT (Subjective Workload Assessment Technique) sebagai acuan untuk variabel beban kerja mental. Peneliti menggunakan dimensi pada metode SWAT untuk menjadi indikator dalam kuesioner yang dibagikan kepada responden. Pernyataan dalam kuesioner beban kerja mental telah disesuaikan oleh peneliti sesuai dengan keadaan di tempat penelitian, sehingga dapat digunakan sebagai alat ukur yang relevan. Kemudian, hasil dari kuesioner diuji reliabilitas dan validitas agar dapat dipertanggungjawabkan secara ilmiah. Hasil dari penelitian ini menunjukkan bahwa beban kerja operator cenderung tinggi, ini bisa dilihat dari skala jawaban responden terhadap dimensi pengukuran beban kerja yaitu skala jawaban responden tinggi terhadap dimensi beban waktu, skala jawaban responden sangat tinggi terhadap dimensi beban usaha mental dan skala jawaban responden tinggi terhadap dimensi beban tekanan psikologis.

b. Hubungan yang ada antara beban kerja mental terhadap kinerja operator proses produksi di seksi purified terephtalic acid (PTA) di PT Mitsubishi Chemical Indonesia ini menunjukkan hasil yang signifikan diantara keduanya dimana kekuatan hubungannya kuat dan arah hubungannya positif, dengan nilai korelasi koefisien rank spearman-nya yaitu $+0,755$. Jawaban responden atas variabel beban kerja mental menunjukkan indikasi beban kerja kerja mental yang tergolong tinggi, di 
sisi lain jawaban atas variabel kinerja juga tergolong tinggi. Sehingga dapat disimpulkan bahwa operator proses produksi bagian purified terephtalic acid (PTA) di PT Mitsubishi Chemical Indonesia memiliki beban kerja mental yang tinggi dan menghasilkan kinerja yang tinggi.

c. Dalam penelitian ini, hasil dari penelitian menunjukkan bahwa kinerja operator dalam kondisi tinggi, hal ini bisa dilihat dari skala jawaban responden terhadap dimensi pengukuran kinerja yaitu dengan skala jawaban responden sangat tinggi terhadap dimensi kualitas, skala jawaban responden tinggi terhadap dimensi kuantitas, skala jawaban responden tinggi terhadap dimensi penggunaan waktu dalam bekerja, dan skala jawaban responden sangat tinggi terhadap dimensi kerjasama dalam bekerja. Dengan demikian tidak dilakukan perbaikan dalam hal kinerja.

\section{Saran}

Berdasarkan hasil penelitian ini, peneliti menyarankan beberapa hal sebagai berikut:

a. Penelitian lanjutan mengenai beban kerja bisa juga dilakukan di seksi lain dengan menggunakan metode yang sama. Dan juga bisa digunakan kembali ketika terjadi perubahan di seksi ini misalnya seperti terjadi perubahan jumlah karyawan baik itu pengurangan dan juga penambahan karyawan yang akan berpengaruh terhadap beban kerja.

b. Perusahaan harus mampu mengontrol perkembangan beban kerja operator dengan mengadakan survey berkala, untuk mengantisipasi beban kerja terlalu tinggi. Karena dari hasil penelitian, beban kerja operator proses produksi bagian purified terephtalic acid (PTA) tergolong tinggi.

c. Dengan kondisi operator yang rata-rata melakukan dua pekerjaan atau lebih dan memiliki waktu luang yang sedikit serta dengan adanya faktor-faktor lain dari internal maupun eksternal operator beban kerja dapat terus meningkat. Apabila beban kerja cenderung meningkat dan melebihi kemampuan para operator akan berakibat pada menurunnya kinerja karyawan. Sehingga peneliti menyarankan agar perusahaan dapat mengontrol beban kerja operator, sehingga kinerja operator dapat terus terjaga. Mengingat sampel yang terbatas, bagi penelitian selanjutnya sebaiknya dilakukan dengan sampel yang representatif sehingga generalisasi penelitian dapat dilakukan pada populasi yang lebih luas.

\section{DAFTAR PUSTAKA}

Artadi, Febri Furqon. 2015. Pengaruh Kepuasan Kerja dan Beban Kerja terhadap Kinerja Karyawan pada PT. Merapi Agung Lestari. Skripsi. Yogyakarta: UNY

Chaterina, Ruth. 2012. Hubungan Beban Kerja dengan Kinerja Karyawan Offshore pada Divisi Quality Assurance Quality Control di Pertamina Hulu Energi ONWJ LTD Jakarta. Skripsi. Depok: UI

Departemen Pendidikan Nasional. 2005. Kamus Besar Bahasa Indonesia. Jakarta: PT. Gramedia Pustaka Utama

Gibson, James L., Ivancevich John M. \& Donelly, Jr. James. 1985. Organisasi Jilid 1 Edisi Kelima. Jakarta: Penerbit Erlangga

Hancock, P.A \& Meshkati, N. 1988. Human Mental Workload. Elsevier Science Publisher B.V. Netherlands

Handoko, T. Hani. 2013. Manajemen Edisi 2. Yogyakarta : BPFE

Hart, Sandra G. and Staveland, Lowell E. Development of NASA-TLX (Talk Load Index): Result of Empirical and Teoritical Research. Jurnal. www.nasa.gov.id, diakses pada tanggal 28 Februari 2016

Hart, Sandra G. 2006. Nasa-Task Load Index (Nasa-TLX); 20 Years Later, http://humansystems.arc.nasa.gov/groups/tlx/downloads/HFES_2006_paper. pdf, diakses pada tanggal 28 Februari 2016 
Hidayat, A.T. 2011. Analisis Pengaruh Shift Kerja terhadap Beban Kerja pada Pekerja di PT. Primarindo Asia Infrastructure, Tbk. Skripsi. Bandung: Universitas Islam Bandung

Ivancevich, John.M. 2001. Human Resource Management. New York: Mc, Grow- Hill Companies

Memarian, Babak dan Mitropoulos, Panagiotis. 2011. Work Factors Affecting Task Demands of Masonry Works. Jurnal. Arizona State University

Panuju, Redi. 1995. Komunikasi Bisnis. Jakarta: PT Gramedia Pustaka Utama

Prasetyo, Bambang dan Lina, M. Jannah. 2012. Metode Penelitian Kuantitatif. Jakarta: PT Raja Grafindo Persada

Priyatno, Dwi. 2014. Mandiri Belajar Analisis Data dengan SPSS. Yogyakarta: Mediakom

Reid, G. B And Nygren, T. E. 1988. The Subjective Workload Assessment Technique: a scaling procedure for measuring mental workload. In P. A. Hancock and $N$. Meshkati (eds), Human Mental Workload, Amsterdam: North-Holland

Robbins, Stephen P. dan Judge, Timothy A. 2014. Perilaku Organisasi Edisi 12. Jakarta: Salemba Empat

Simamora, H. 2004. Manajemen Sumber Daya Manusia. Edisi Ke-3.Yogyakarta: STIE YKPN

Simanjuntak, Risma Adelina. 2010. Analisis Pengaruh Shift Kerja terhadap Beban Kerja Mental dengan Metode Subjective Workload Assessment Technique (SWAT). Jurnal. Yogyakarta: FT Institute Sains \& Teknologi AKPRIND Yogyakarta

Sudarmanto. 2009. Kinerja dan Pengembangan Kompetensi SDM (Teori, Dimensi Pengukuran, dan Implementasi dalam Organisasi). Yogyakarta: Pustaka Pelajar

Sugiyono. 2007. Metode Penelitian Administrasi. Bandung: PT Alfabeta

Tanireja, T. dan Mustafidah, H. 2014. Penelitian Kuantitatif. Bandung: Alfabeta

Wijono, Sutarto. 2010. Psikologi Industri \& Organisasi. Jakarta: Kencana

Yamin, Sofyan dan Kurniawan, Heri. 2014. SPSS Complete. Jakarta: Salemba Infotek. 
